\title{
ESCRIBE CIEN VECES: "NO ME REIRÉ DE LOS PROFESORES". (HUMOR, SÁTIRA ACADÉMICA Y NOVELA DE CAMPUS RECIENTE EN ESPAÑA)
}

\author{
JAVIER GARCía RODRÍGUEZ \\ Universidad de Oviedo
}

La vida universitaria, solía observar el doctor Johnson, nos enfrenta muy raras veces con las formas violentas de la muerte.

Michael Innes, Muerte en la rectoría

Preámbulo

Universidad de Cornell, Ithaca (Nueva York). En 1983, el pensador Jacques Derrida ofrece una conferencia con el título de "Las pupilas de la universidad. El principio de razón y la idea de la universidad". Y comienza su intervención con esta pregunta retórica:

¿Cómo no hablar, hoy, de la universidad? Le doy una forma negativa a mi pregunta: ¿cómo no...? por dos razones. Por una parte, como todo el mundo sabe, resulta más imposible que nunca disociar el trabajo que realizamos, en una o varias disciplinas, de una reflexión acerca de las condiciones político-institucionales de dicho trabajo. Esta reflexión es inevitable; no es ya un complemento externo de la enseñanza y de la investigación, sino que ha de atravesar, incluso afectar a los objetos mismos, a las normas, a los procedimientos, a los objetivos. No se puede no hablar de ella. Pero, por otra parte, mi "cómo no..." anuncia el carácter negativo, digamos mejor preventivo, de las reflexiones preliminares que desearía exponerles aquí. (Derrida 1989: 62)

1. De algunas CONDICIONES DEL HUMOR (Y LA RISA)

El humor es un arma de defensa y ataque. Participa, al mismo tiempo, de contenidos de carácter individual en el espacio de la producción (creatividad, originalidad, imaginación...) y de orden social en el de la recepción (códi- 
go compartido, intersubjetividad, análisis del contexto, doxa...). Moviliza, a su vez, componentes racionales (análisis de la realidad, narratividad, dramatización aceptada) e irracionales (ficcionalidad e inverosimilitud en grados variables, semántica transracional, componente lúdico extremado, etc.). Y se nutre, por fin, de criterios de subversión controlada (liberación psicológica) y de pertenencia a una comunidad (existencia de unos límites). De tal modo que, partiendo de los principios de identidad, contradicción, transferencia y contigüidad planteados por Hernández Guerrero en su reflexión sobre el humor literario (2010: 45-49), podríamos referirnos al humor como un procedimiento creativo y recreativo que alcanzaría tal magnitud humana y social que "(la) visión de la vida desde la risa es hasta tal punto la más universal de las constantes culturales que tenemos la impresión de que carece de comienzo" (Hernández Guerrero 2010: 50). La universalidad del humor y su participación en el pálpito cultural conducen a la reflexión en torno a la relación que este mantiene con la capacidad del ser humano para verse a sí mismo como un ente "risible", para entenderse en el espejo de la cotidianidad ridícula, para superar las limitaciones a través de la proyección de sí mismo como un reflejo ridens et ridiculus ${ }^{1}$. De ahí que, por su parte, al analizar el fenómeno del humor desde una perspectiva freudiana, escriba Isabel Paraíso:

Lo grandioso del humor reside, según Freud, en el triunfo del narcisismo, en la confirmación victoriosa de que el yo es invulnerable. En el humor, el yo rehúsa dejarse ofender y precipitar al sufrimiento por causa de la realidad; se empecina en que no pueden afectarlo los traumas del mundo exterior. Más aún: demuestra que el mundo exterior solo está representado por motivos placenteros. Este último rasgo es absolutamente esencial para que el humor llegue a producirse.

El humor no es resignado, sino rebelde. Significa no solo el triunfo del yo, sino también el triunfo del principio de placer, que consigue elevarse sobre las circunstancias reales adversas. (Paraíso 1995: 113)

La asunción del humor como un componente humano ineludible (Ziv y Diem 1989), rastreable no solo como material empírico creativo y recreativo, sino como elemento característico - desde las formas literarias más simples a las formas más complejas, si seguimos la nomenclatura de André Jolles (1930)²- de buena parte las creaciones literarias consideradas en su dimensión historizable (Beltrán 2002), queda patente en los distintos desarrollos teóricos que ha man-

\footnotetext{
1 Tomo este sintagma del título de Juan Carlos Pueo (2001) "Ridens et ridiculus". Vincenzo Maggi y la teoría humanista de la risa. Este mismo investigador ha dedicado otra monografía a asuntos afines en Pueo (2002).

${ }^{2}$ André Jolles, en sus Formas simples de 1930, aboga por la existencia de una serie de formas de lenguaje que se dan de manera natural, sin intervención artificial por parte de ningún creador, y que corresponden a la forma en que responde el lenguaje a determinadas actitudes humanas. Solo la manipulación estética de estas formas simples va dando lugar, a juicio del holandés, a las formas simples evolucionadas y, después, a las formas complejas o literarias. Una de las nueve formas simples originarias es el chiste, que responde a la actitud del ser humano ante lo cómico o ante la risa.
} 
tenido el estudio del humor3: de la línea freudiana anteriormente planteada al tradicional modelo establecido por Escarpit en su estudio tan citado El humor (1962), o de la línea propuesta en 1967 por Fernández de la Vega tratando de desentrañar algunas de las recónditas razones en El secreto del humor a la "dulce locura", como da en llamarlo William F. Fry en Sweet Madness: A Study on Humor (1968), de las variantes estructuralistas con las que Violette Morin (1982) caracteriza el chiste considerado como forma cómica del relato al tratamiento que el humor establece con "lo cómico" en Ensayo preliminar sobre lo cómico (Victoria 1958), de las estrechas relaciones pero también las sutiles diferencias entre humor, ironía y parodia (VV.AA. 1980) hasta llegar al concepto de post-humor que sustenta la teoría de la nueva comedia (Costa 2010) ${ }^{4}$. No es, solamente, la necesidad de cartografiar las líneas que delimitan los espacios donde habitan las distintas categorías teóricas o psicológicas, sino, más bien, incardinar estos espacios en una teoría de la experiencia estética, como proponía Jauss al tratar de establecer los límites entre lo ridículo y lo cómico (1986: 201-215). En este sentido, se pregunta Jauss:

\begin{abstract}
A juzgar por el modo en que lo ridículo y lo cómico se manifiestan, ¿es posible trazar una línea divisoria entre vida y arte, entre comportamiento pragmático y actitud estética? Si es así, ¿dónde empieza la experiencia estética específica? $y$, en este acto de reír, ¿hasta qué punto puede decirse que lo estético penetra - de modo progresivo o retroactivo- en el pragmatismo de las experiencias entornables? (Jauss 1986: 201)
\end{abstract}

\title{
2. LA SÁTIRA
}

Humor y risa no son intercambiables (Fernández de la Vega 1967: 117-124), del mismo modo que lo cómico y el humor participan de elementos comunes sin poder ser considerados idénticos. Y trazando un modelo binario, diríamos que tristeza y lágrimas tampoco. Wayne C. Booth, en su demorada y profunda glosa del conocido trabajo de Ortega y Gasset "Notas sobre la novela", postula, a través del título de uno de los capítulos de su Retórica de la ficción, un principio teórico que conduce al trasvase del resultado de los procesos cómicos y trágicos desde los principios subjetivos y sentimentales que los provocan hasta su uso en el ámbito creativo institucionalizado. El neoaristótelico titula: "Las lágrimas y la risa son, estéticamente, fraudes" (Booth 1986: 119-125). Son ficciones, diríamos, si queremos expresarlo de manera menos radical.

El humor, la comicidad, la risa, el chiste, alcanzan su dimensión literaria primigenia en la sátira, un género que "por haber existido [...] como género literario y porque este estatuto le ha conferido una superioridad sobre otras prác-

\footnotetext{
${ }^{3}$ Nos referimos, por supuesto, a desarrollos recientes. Podríamos, claro, volver la vista tan atrás como a la Retórica clásica (Quintiliano, tal vez, para empezar) o a la Poética (lo risible como parte de lo feo, el personaje con defectos que no causan dolor ni ruina, como parte ineludible de la comedia en Aristóteles, por ejemplo).

${ }^{4}$ Un resumen muy cabal de estas y otras cuestiones puede encontrarse en el detallado estudio de Schoentjes (2003). Valiosos apuntes pueden encontrase también en Ballart (1994).
} 
ticas más localizadas" (Schoentjes 2003: 186) se ha mostrado siempre como el referente literario por excelencia con una peculiaridades muy destacadas:

La sátira, la parodia, la ironía, la broma, la comicidad tienen nombres antiguos y provocaron viejas risas. Son cosa de risa, mientras que el humor es su enemigo [...]. Tal vez se pueda hablar de una sátira moderna de matiz humorístico. Pero la sátira de tipo clásico, aún viva, no es más que una forma especial de la comicidad: sátira cómica, ridiculización, risa a cuenta del satirizado. (Fernández de la Vega 1967: 117)

La sátira persigue la risa atacando a individuos o a actitudes que se entienden como perniciosos para la sociedad (Worcester 1960). Se nutre, sin duda, del estereotipo, del ataque indiscriminado, de la exageración, de la crítica a las identidades prefabricadas y dañinas. El escritor satírico, frente al cómico, al irónico, al paródico o al elegantemente humorístico, propone sin pudor la intentio auctoris, la expone a la convalidación del lector sin apenas intermediarios que maticen sus propósitos. La exégesis del lector es siempre pragmática, más allá del valor estético. Desde una posición de superioridad que le viene otorgada por el convencimiento -muchas veces espurio-del control sobre su propia máscara, el lector anticipa el sentido transgresor, hiriente, de la afilada crítica hacia unos actos grotescos merecedores de burla, unos valores morales a los que hay que atacar por dañinos y unos protagonistas de los que hay que reírse por mostrencos y ridículos. El estudio de la sátira en la novela ha de atender necesariamente a la original batería de propuestas de Mijaíl Bajtín (1986; 1989a; 1989b), sobre todo en el tratamiento del género mediante la carnavalización del humor a partir de la reelaboración y actualización de los rasgos básicos de la sátira menipea, que quedan resumidos en su Problemas de la poética de Dostoievski (1986: 114 119): presencia de elementos cómicos, libertad de argumento y de invención filosófica, uso de lo fantástico creando situaciones extraordinarias, combinación de lo místico con lo naturalista, inclusión de interrogantes últimas, mundo en tres niveles, experimentalismo fantástico, experimentación moral y psicológica, conductas excéntricas y escándalos, agudos contrastes y combinaciones, utopía social en sueños o viajes, inserción de otros géneros mezclando prosa y poesía, estilos y tonos múltiples, y finalmente, preocupación por los problemas del presente.

El ejercicio de la sátira sobre el mundo universitario respondería muchos de los rasgos establecidos por Bajtín, a los que habría que añadir, a nuestro juicio:

a) un intento consciente de subversión contra la autoridad y el poder representados por la figura del profesor $y$, en menor medida, de los responsables académicos (haciendo de ellos depositarios de los contravalores éticos e intelectuales que no se esperarían). Una manera, en suma, de contravenir las técnicas de poder Michel Foucault le suponía a las instituciones coercitivas y que, en cierta medida, y con matices, podrían ser aplicables a la universidad: vigilancia, 
normalización, exclusión, clasificación, distribución, individualización, totalización y regulación ${ }^{5}$.

b) el modo en que la ficción se revuelve simbólicamente contra sus disciplinas asociadas y, tal vez, parásitas: la crítica, la historia literaria, etc. En un ejercicio de "venganza ficcional", la sátira académica reproduce, exacerbados, los que considera los vicios más destacados de aquellos que viven de ella (Concha 1988).

c) la moda antiintelectualista y antiteórica, tan en boga en los ochenta y en los noventa, que avanzó por la vía del neopragmatismo desde la resistencia a la teoría de Paul de Mann (extraño caso de esquizofrenia pro y antiteórica), pasando por la Against Theory de Knapp y Michaels, y llegando a las "imposturas intelectuales" de los muy publicitados Sokal y Bricmont.

La sátira, entonces, encuentra un valioso caldo de cultivo en el campus, un teatro de variedades donde abundan los géneros diversos y un elenco variado de protagonistas y secundarios condenados a la caricatura y al escarnio (Bosco y Connor 2007; Elliot 1960; Paulson 1967).

\section{Novela de CAMPUS: Un PANORAMA DEL GÉNERO}

Las amplias posibilidades narrativas de un espacio cerrado con sus propias -y en ocasiones incomprensibles- reglas, las rendijas por donde se desliza la parodia, la oportunidad de una crítica corrosiva de determinadas prácticas sociales, la sátira más o menos bienintencionada de las relaciones humanas o la valoración de ciertas instituciones y su presencia pública son algunas de las razones que pueden explicar el hecho de que autores de reconocido prestigio, algunos con vitola de clásicos, hayan sentido la tentación en los últimos cincuenta años de convertir en ficción narrativa las vivencias y apariencias, las relaciones y ambiciones del mundo académico, bien que con las peculiaridades propias de cada opción estilística o de cada orientación temática: la estricta farsa académica (Tom Sharpe), la parodia intertextual (David Lodge), lo políticamente correcto (J. M. Coetzee, Philip Roth, Don DeLillo), los modelos detectivescos (Amanda Cross, Joan Smith, Batya Gur), las variantes más o menos posmodernas (John Barth, Vladimir Nabokov), el compromiso político (Malcolm Bradbury, Saul Bellow, Kingsley Amis), la metaficción historiográfica (A. S. Byatt, Edmundo Paz Soldán) o la reflexión teórico-literaria estricta (Gilbert Adair, Carol Shields, Paule Constant). La suma de estos modelos parciales puede dar una cabal definición de lo que ha sido y es actualmente la novela de campus (Bevan 1990; García Rodríguez 2002; Reddall 2010; Showalter 2005; Wiegenstein 1997).

Dentro de esta etiqueta caben los argumentos y las escenas más disparatados, hecho fácil de comprobar después de un apresurado catálogo de los mismos: un reputado teórico de la literatura sospechosamente parecido a Paul de Man trata de ocultar su pasado inventándose una falsa biografía. Un grupo

${ }^{5}$ Queda ahora solo apuntada la necesidad de reflexionar debatir sobre estas cuestiones. Un resumen de los principales puntos de debate puede encontrarse en <http://www.odiseo.com. $\mathrm{mx} / 2005 / 07 /$ barraza-saberypoder.htm>. 
de prostitutas irrumpe en un multitudinario congreso de la Modern Languages Association. Un filósofo en año sabático trata de explicar la noción heideggeriana del Dasein mediante un programa informático. En la desaparición de un profesor de Literatura el principal sospechoso es un deconstruccionista paranoico. Un estudiante de doctorado de crítica literaria es asesinado en la Universidad de Nueva York. Un profesor ayudante adquiere poderes sobrenaturales tras serle reimplantado un dedo seccionado en un accidente, hecho que le permite imponer su voluntad a los demás. Para tratar de solucionar los constantes enfrentamientos entre las dos facciones del mismo departamento (clásicos y modernos, teóricos y filólogos, defensores de la literatura tradicional y los que se refieren a ella como una más de las "prácticas discursivas", Turks y Fools), aparece una misteriosa y omnipotente joven profesora capaz de hacer realidad los deseos íntimos de cada uno de los protagonistas, convertidos ya en personajes de novela dentro de la novela. En un departamento de Física donde tratan de recrear el origen del Universo consiguen abrir un agujero negro ("Ausencia") que termina por convertirse en la estrella absoluta del campus, tanto por lo que tiene de desafío a las leyes físicas como por el hecho aparente de tener una personalidad propia al ser capaz de absorber objetos de forma selectiva. Un cerdo transformado en icono y objeto de deseo de todo un campus del Medio Oeste americano. Un manuscrito de Rabelais robado de la biblioteca de la universidad y las iniciativas de las distintas facciones de profesores para recuperarlo. En un hipotético futuro de guerra económica entre Estados Unidos y Japón, la vida académica ha conducido a una guerra declarada entre los viejos miltonianos por un lado y los deconstruccionistas y neohistoricistas por otro.

Más allá de las líneas creativas que pueden observarse en Europa continental y en la India, la novela de campus es un género anglosajón (Bostock 1989; Caram 1980; Lisherness 1985; Lyons 1962; Maddok-Cowart 1989; Meers 1953; Moseley 2007; Sáiz García 2001; Verrone 1999). En su implantación en los primeros años cincuenta fueron fundamentales, más allá de las estrictamente literarias, algunas razones de carácter político, social e ideológico: persecuciones políticas, control ideológico, comités de infausto recuerdo, pero también el hecho de que aquellos fueran años de recuperación económica y de un espectacular desarrollo de las instituciones de educación superior. Por otra parte, el auge del género en Inglaterra coincide con un momento de crisis económica y educativa en los años setenta y ochenta, de modo que la novela se convierte en contrapunto humorístico y paródico (siempre la vieja tradición humorística británica) de una caótica situación social y de una política de recortes presupuestarios y de cierre de instituciones, algunos de cuyos efectos todavía perduran en nuestros días. Por último, el relevo tomado a partir de los años ochenta en los Estados Unidos, momento que marca el inicio del florecimiento $y$, en cierta medida, del establecimiento formal y temático del género, coincide con otro estado de crisis: el de la institución universitaria en general y el de las Humanidades en particular, que, en un círculo vicioso, es causa y efecto a la vez de situaciones como la desproporción en el mercado laboral entre oferta y demanda de titulados superiores (con su consiguiente hiperespecialización), la presión desde el exterior 
del propio sistema por resultados tangibles y mensurables, el desprestigio de la enseñanza superior, etc. (Rossen 1993; Womack 2002).

Así, entre las elitistas universidades de la Ivy League, las tradicionales universidades estatales del Medio Oeste, los vetustos campus de Oxbridge o los impersonales edificios de ladrillo rojo, aluminio y cristal de las provincianas universidades inglesas, 0 , ya en sus dobles de ficción, asistimos a la presentación de personajes excéntricos, estrellas académicas, caricaturas excesivas tratadas sin piedad, personajes atrabiliarios que nadan en las turbias aguas de la vida y política universitarias (las clases, la investigación, los comités permanentes, las modas teóricas, los recortes, las tribus académicas ${ }^{6}$ ):

El campus es lugar de paseo y ficción del mundo. Pero es también isla alejada del mundo, una torre de marfil para jóvenes mentes. Este carácter viene subrayado por el hecho de que es un lugar donde el tiempo se cuenta por semestres y años académicos, que principian en septiembre, y donde se practica un juego de roles, se "juega" a aprender a ser mayor. (Bou 2006: 6)

Con los nombre de novela de campus, novela académica o University Fiction, se conoce, pues, el género ${ }^{7}$ en el que se incluyen las narraciones que se centran primordialmente en la vida, la política y las relaciones de profesores y personal en un ambiente académico. Pueden tener muy distintas formulaciones subgenéricas, porque se mezclan con otras formas: sátira académica, farsa académica, novela policiaca, etc. $Y$ no es, a nuestro juicio, como algunos se empeñan en manifestar, un género menor, un mero entretenimiento. Estamos persuadidos de que el análisis de la representación de lo académico en la ficción contemporánea (incluimos aquí también el cine y las series, que quedan fuera de nuestro alcancen en este momento) puede ofrecer resultados excelentes para el análisis de conceptos de índole estrictamente literario (se discuten cuestiones como el significado, el pluralismo, la metodología, la paradoja, la historia, el simbolismo, la intención, la construcción, la fijación del canon, la estructura, la mímesis, la originalidad, el relato, el realismo, la unidad, la influencia moral de las obras), pero también de otros como el poder, el conocimiento y su transmisión, el concepto de libertad, lo institucional y la autoridad, las relaciones de grupo, los asuntos éticos, la interrelación individuo-colectivo, o las de sexo, lo relativo a las reglas, los sistemas educativos, las utopías, el control de la información, etc. El tránsito de los modelos formalistas o contenidistas (filológicos, historicistas, estéticos, si se quiere llamar así) hacia modelos más abiertos o "teóricos"

\footnotetext{
${ }^{6}$ Con título tan significativo caracterizó ya la situación Hazard Adams en 1976 en su libro The Academic Tribes. Tuvieron que pasar casi diez años para que se diera a estas tribus su espacio en la evolución de la especie humana. Lo hizo Pierre Bourdieu en su conocido ensayo Homo Academicus (2008, or. 1984). En España intentó un extenso catálogo académico Sixto Sánchez Lorenzo en su De Bestiis Universitatis (Esos tipos universitarios...) (2003).

${ }^{7}$ No es esta la ocasión para entrar en disquisiciones sobre el concepto de género y su aplicación a la novela de campus. Nos limitamos a hacer un uso general del término, en el sentido de clase textual con contenidos semánticos comunes. Probablemente sería más ajustado denominarlo "subgénero", en cualquier caso, atendiendo a su especificidad semántica.
} 
(más cercanos a los Cultural Studies con todas sus variantes) podría hacerse sin mucha dificultad atendiendo a los distintos desarrollos de la novela de campus, que incide en sus modelos recientes en conceptos como alienación, logocentrismo, diseminación, sexualidad, abismo cognitivo, energía social, relativismo extremo, lectura de suspicacias, descanonización, campos de conflictos, diáspora, poder, estrategias, alteridad, margen, dialogismo, hegemonía, orientalismo, rizoma, subalterno, institucionalización, fragmentación, sujeto escindido, paradigma, postcolonialismo, arqueología, teoría del caos, desterritorialización... La idea que tratamos de desarrollar quedaría bien ejemplificada en la comparación que establece Frederick C. Crews entre los principios teóricos y los modelos de análisis posibles en 1963 y en 2002 aplicados al estudio de un libro tan poco sospechoso como las aventuras de Winnie the Pooh (Crews 1963 y 2002), que aunque son más novela de campo que de campus, dan muy bien la medida del aspecto que estamos tratando:

En 2002, el propio Crews publica -bajo el mismo esquema- una secuela de su Pooh Perplex con el título de Posmodern Pooh, en el que analiza la transformación de las disciplinas académicas. Pero lo que en 1963 era un rastreo y un muestrario paródico pero objetivo, una celebración de las posibilidades de la crítica, es ahora un claro ataque a lo que él entiende como excesos del pensamiento académico post-sesentero: oscuridad, impostación, abandono de los criterios, politización extrema, descanonización, jerga incomprensible, aburrimiento, dominio de lo teórico, discurso autorreversible, incapacidad para exceder el ámbito académico, cinismo, descreimiento de cualquier tipo de valor. Para ello se vale del pastiche de las lecturas postestructuralistas, marxistas, feministas, neohistoricistas, postcolonialistas y ciberteóricas. El tiempo, evidentemente, pasa deprisa en el Bosque de los Cien Acres. (García Rodríguez 2009: 92).

\section{Campus nOVEl a la española}

¿Tendrá razón Enric Bou, quien conoce de primera mano ambos sistemas, en que "el campus es isla, espacial y temporal, lugar para el estudio. Un espacio que no tiene correspondiente en el sistema universitario español?" (2006: 6). Si no sonara tan obvio podríamos asegurar entonces que en España no hay novela de campus porque no hay campus. $O$ al menos no un campus al que se le pueda poner las puertas que permitan encerrarlo en los márgenes más o menos estrechos de una novela satírica. Con todo, la literatura española de las últimas décadas ha ofrecido algunas muestras de novela de campus en sus distintas variantes temáticas y en proporciones también variadas: de la novela policiaca o detectivesca al costumbrismo burgués pasando por la ciencia ficción, por citar solo algunas (siendo cierto, por otra parte, que algunos de estos ejemplos no tendrían una adscripción fácil al género aunque mantengan con él una relación cercana) $)^{8}$. Si hacemos un repaso no exhaustivo a este muestrario,

\footnotetext{
${ }^{8}$ Quedan fuera de nuestro propósito actual las novelas de campus escritas en España pero en una lengua distinta del español, como la reciente en catalán de Max Besora, La técnica meravellosa
} 
sin más pretensión que dejar constancia de esta variedad en los temas, en los géneros y en la vertiente literaria y estilística de los autores, encontramos los siguientes autores y obras: Josefina Aldecoa (El enigma, 2001), Antoni Casas Ros (Enigma, 2010), Javier Cercas (El inquilino, 2000; La velocidad de la luz, 2005; El vientre de la ballena, 2007), Saúl Fernández (En medio del invierno, 2011), Juan Francisco Ferré (Providence, 2009), Marcelo García (Instrucciones psicóticas para no seguir en épocas de crisis, 2009), Manuel Jurado López (Cómo matar a un poeta, 2008), José Antonio Leal Canales (El testamento del becario, 2010), Elvira Lindo (Algo más inesperado que la muerte, 2002), José Ángel Mañas (Soy un escritor frustrado, 1996), Javier Marías (Todas las almas, 1989), Xavier Moret (El impostor sentimental, 1997), Marta Rivera de la Cruz (La importancia de las cosas, 2009), Antonio Muñoz Molina (Carlota Fainberg, 1999), Antonio Orejudo (Un momento de descanso, 2011), Francisco Parra Luna (Campus adentro, 2011), José María Pérez Collados (El tren de cristal, 2011) ${ }^{9}$, Javier Piqueras de Noriega (La cátedra, 2003; El congreso, 2005), Javier Rodríguez Alcázar (El escolar brillante, 2005), Antonio J. Rodríguez (Fresy cool, 2012), Gregorio Salvador (El eje del compás, 2002), Gonzalo Torrente Ballester (La muerte del decano, 1992), Pablo Tusset (Oxford 7, 2011), Carlos Villar Flor (Calle menor, 2004). ${ }^{10}$

No parece, a primera vista, una lista muy nutrida. Las razones de esta escasez no nos competen ahora mismo, $y$, de hecho, se hace imprescindible ya, más allá de intuiciones agudas o de opiniones interesadas, un estudio cabal que explique este hecho. Pero sí es significativo cómo la enumeración nos permite reconocer a autores que cubren prácticamente todas las promociones que tienen actividad literaria actualmente, así como una variadísima adscripción estilística. Esto es, el sistema género "novela de campus" ha alcanzado un estado de institucionalización que permea estilos y generaciones, de tal modo que, más allá de sus diferencias evidentes y su escasa presencia, aparece integrado en el sistema literario español con naturalidad. El recuento nos permite, por otra

(2014). Y también las que provienen del ámbito latinoamericano, como sería el caso de las obras de los argentinos César Aira (El congreso de literatura), Guillermo Martínez (Los crímenes de Oxford y Yo también tuve una novia bisexual) y Pola Oloixarac (Las teorías salvajes), del uruguayo Rafael Courtoisie (Goma de mascar), de los chilenos José Donoso (Donde van a morir los elefantes) y Sergio Gómez (La obra literaria de Mario Valdini), del colombiano Santiago Gamboa (Necrópolis) o del boliviano Edmundo Paz Soldán (La materia del deseo). Algunas ideas sobre la ficción latinoamericana y su relación con la universidad estadounidense puede verse en Kerr (1997) y en el trabajo de Reati y Ocampo (1998).

${ }^{9}$ Este mismo autor, profesor en la Universidad de Girona, es responsable del "Premio Nacional Novela de Campus" que, desde 2013 organizan la Red de Universidades para la Lectura y la Universidad de Girona, con el fin de promocionar el género en el ámbito español.

${ }^{10}$ No querríamos dejar pasar la ocasión para mencionar, para que quede constancia, la existencia de una serie de poemas que configurarían un mínimo florilegio de poemas de campus: "Grupo de hombres (Faculty Meeting)", de Julia Uceda; "Curso de Estudios Hispánicos" y "Mesa redonda", de Miguel d'Ors; "Hombre de lunes con secreto", de Luis García Montero; "Género profesor (de Teoría literaria-Lírica)", de José Luis Piquero; "Eruditos en campus", de Ángel González; "Campus americano", de Juan Antonio González Iglesias; "Oración en Columbia University", de José Hierro; "Un poema de campus", de Jaime Siles; "El banquete", de María do Cebreiro; "Fin de curso", de Rodrigo Olay; toda la sección primera del libro Papel de envolver, de Rafael Valdivieso; y, en parte, el clásico "A mi antiguo profesor de Preceptiva", de Rafael Montesinos, y "Profesora", de la esquiva Leticia Bergé. Por no hablar de los gallos medievales y los vejámenes, prehistoria del género. 
parte, dar cuenta de una realidad: no todas tienen el humor o la sátira como elemento central, ni siquiera tangencial. De hecho, en la mayoría, la gravedad, la reflexión, la memoria o el apunte costumbrista, el documento sociológico o la introspección psicológica es lo que prima dentro de una estructura narrativa de carácter más convencional, convirtiendo el espacio universitario en un espacio anodino, un simple escenario sin más importancia que la de servir como decorado para el desarrollo de la trama, en vez del elemento dinámico que determina las vivencias de los personajes y los motivos de sus relaciones. Con todo, la sátira es el elemento central de algunas de estas novelas de campus, algunos de cuyos elementos constructivos, validaciones genéricas y características propias nos disponemos a presentar brevemente a continuació $n^{11}$ :

\subsection{El impostor Sentimental (Xavier Moret)}

El catalán Xavier Moret establece como punto de partida para su novela El impostor sentimental las peripecias vividas por su protagonista y narrador, Víctor Más, al encontrarse como "impostor" en el ámbito que mejor define, a su juicio, el espacio más improductivo del mundo académico (al menos en las Humanidades): un congreso de literatura. Esto le sirve para plantear un enfrentamiento entre "la teoría" como enclaustramiento en el mundo de los conceptos, mientras sus usuarios se distancian del objeto de su reflexión: el texto literario. Esta disputa entre texto primario y texto secundario, entre creación literaria y (re)creación teórica que contienden por la hegemonía en los discursos según las modas, es lo que pone en tela de juicio desde una perspectiva lúdica El impostor sentimental, siguiendo las huellas del humorismo inglés -la más cercana la de David Lodge (El mundo es un pañuelo, ¡Buen trabajo!) ${ }^{12}$ y la más lejana pero aún más ilustre de Laurence Sterne (La vida y opiniones del caballero Tritam Shandy) (Sosa Antonietti 1999).

Concebida como obra netamente metaficcional, la novela se desarrolla como una sátira académica que instila sus dardos críticos en un envoltorio que, al mismo tiempo, también se percibe como una ficción que no carece de humor: "En general, la novela de metaficción se refiere a sí misma, en gran medida o totalmente, llamando la atención sobre su propia forma y construcción sin ocultar -por el contrario, poniendo de manifiesto- su condición de obra de ficción, de ilusión creada" (Dotras 1994: 11). El impostor sentimental se sirve constantemente de las técnicas y estrategias que abundan en la fractura de la ilusión referencial

\footnotetext{
${ }^{11}$ Hemos optado por novelas menos conocidas, y dejamos, por distintos motivos, fuera de este breve recorrido algunos otros títulos: Un momento de descanso, Antonio Orejudo, ha recibido recientemente justa atención crítica que premia una obra muy conseguida (Leuzinger 2014; Rueda 2014; Villanía 2015); y, sin tiempo para mayor consideraciones, nos llega noticia de la nueva novela del poeta y narrador David Refoyo El día después (2014), que al parecer indaga en el intento de un profesor universitario de demostrar su teoría conspiranoica en torno al mundo del fútbol profesional.

12 La bibliografía sobre David Lodge y sus novelas de campus es abundante. Citamos, por su especificidad con los asuntos tratados, la siguiente: Bostock (1989), Lambertsson (1993) y RansellKóster (2001).
} 
y ponen de manifiesto el artificio literario, para llegar a producir la sensación de que la novela se está escribiendo en el instante en que es leída. Así, encontramos en esta novela de campus que es a la vez una parodia de una novela de espías los siguientes rasgos (Dotras 1994: 30-31):

- Tematización abierta sobre las relaciones entre los distintos componentes del texto como acto comunicativo (relación entre autor y texto, texto y lector, el hecho mismo de escribir, el lenguaje novelesco).

- Teorización sobre el arte y sobre la índole de la naturaleza de la ficción en general.

- Mise en abyme o "novela dentro de la novela".

- Presencia autorial autoconsciente y dramatización del autor histórico dentro del relato.

- Intrusión del narratario para efectuar comentarios sobre la propia narración.

- Alusiones directas al lector.

- Transgresión práctica o discusión teórica de determinadas convenciones literarias.

- Manipulación del tiempo y el espacio narrativos.

- Autonomía del personaje consciente de su estatuto ficcional.

¿Qué encontramos en El impostor sentimental? Como dice el propio autor: un congreso de literatura como telón de fondo, una intriga necesaria (historia de espías), un narrador-personaje que es el hilo conductor de la novela y que hace todas las digresiones necesarias para completar la acción. Saltos al pasado que explican los motivos de su asistencia al congreso, cómo conoció a su novia, sus inicios en el periodismo, el éxito de su primera novela. Digresiones, relatos intercalados, que ocupan a veces capítulos enteros y que también sirven, con intención satírico-burlesca, para hablar del mundillo de los escritores, de los premios literarios, de la edición, de las promociones...

Las alusiones literarias aparecen siempre en clave de humor, incidiendo en las fisuras que "lo canónico" ofrece a una mirada inquieta y aguda. Por las páginas de El impostor sentimental circulan Hegel, Benjamin, Jünger, Joyce o Beckett, y se hacen reconocimientos a Le Carré, Lodge, Sharpe, Rabelais o Perec. Y donde también se ataca despiadadamente a la Deconstrucción o se hacen chistes sobre Derrida. Todo ello en una ceremonia de suplantación de personalidades que tan bien cuadra a la transgresión genérica y al juego dialógico que establece la obra. Obligado a ser "otro", Víctor Más celebra la impostura mimetizándose con un ambiente y unos personajes que han hecho de esa impostura su marca vital. Con este simple diálogo entre Víctor Más y su jefe, el cínico Narciso Maluquer se produce el "envío del héroe", se le dota de armas y se le anticipa su misión:

-¿Sabes algún chiste sobre la deconstrucción? -añadió.

-¿Qué? 
- Las corbatas chillonas y los chistes sobre Jacques Derrida y su teoría literaria de la deconstrucción son las bases de cualquier congreso -me aclaró- con aire de suficiencia. Ya te contaré alguno antes de que te vayas. (Moret 1999: 21)

Superficialidad, vacuidad, son las notas características. Los congresistas, profesores, escritores se muestran siempre en una competencia feroz por ser el más ingenioso o por ofrecer la cita más alambicada. El narrador-protagonista va también, a su modo, construyendo la imagen de un "escritor", imagen que se confundirá con la del autor empírico ya que, consecuentemente con los objetivos autorreflexivos de la novela de metaficción, dicho escritor irá escribiendo (o intentando escribir) una novela. La adopción constante de dobles identidades por parte de Más se queda corta en su experiencia de suplantación frente a otros personajes como la danesa doble o triplemente impostora. La fricción entre el mundo real y el mundo ficcional será el resultado de las permanentes interrupciones del hilo discursivo, como si el narrador quisiera quebrar el ilusionismo mimético cada vez que el lector se siente tentando a identificarse con tal o cual situación. Esta línea zigzagueante entre "realidad" (plano al que pertenece el narrador) y "ficción escritural" (proceso de escritura de la novela del narrador) constituye el andamiaje de la totalidad del texto.

\subsection{Carlota Fainberg (Antonio Muñoz Molina)}

Publicada por entregas en el diario El País a lo largo del mes de agosto de 1994, Carlota Fainberg, esta novela corta conjuga la novela de campus por un lado -"off campus" (García Rodríguez 2002: 8)-y un personal modelo de novela "con fantasma" en el que echa mano, además, del homenaje no disimulado a la obra de Borges. Tiene, por tanto, dos líneas argumentales bien diferenciadas: la que proviene del profundo conocimiento que Muñoz Molina posee del mundo estadounidense y de su sistema educativo por un lado, y la de la historia amorosa en Buenos Aires. La primera le permite a su autor desarrollar su capacidad para la sátira y para la caricatura, al tiempo que abre la puerta al análisis del encuentro intercultural al poner en conflicto dos modos de ver el mundo, dos modelos de comportamiento, en un choque cultural que intenta ir más allá del tópico: carne de estudios trasatlánticos... La segunda historia se inscribe en la anterior como un relato intercalado, creando así una estructura narrativa muy compleja. Y es en esta estructura en la que se encuentra ubicado el choque que representan Marcelo y Claudio, dos españoles que se ven obligados por las circunstancias climatológicas adversas a compartir varias horas en un aeropuerto norteamericano. Claudio, de origen español pero expatriado en Estados Unidos donde trabaja como profesor universitario de Literatura, coincide con Marcelo, ejecutivo de una empresa española. El lector percibe muy pronto en qué punto va a producirse el conflicto:

Los dos personajes tienen mucho de estereotipos por cuanto Claudio es petulante, un poco asocial, reflexivo, intelectual, ha interiorizado tanto el sistema de vida americano que incluso analiza en una especie de spanglish el discurso 
narrativo de Marcelo. Este, por su parte, es expansivo, "bocazas", exagerado en las formas y en el fondo, extrovertido y caracterizado con los tópicos mejores y peores del españolismo. (García Rodríguez 2002: 9)

No hay situación o personaje en esta novela que no reciba su ración de censura moral: por un lado, el español transterrado que ha hecho de la autoconsciencia lingüística su marca de distanciamiento de los valores y modales de su patria, que considera obsoletos y tercamente anticuados, que ha hecho del code switching su barrera contra el pasado y su modo de integrarse en su nuevo país, que participa de las modas teóricas más por inercia que por convencimiento, que racionaliza cada uno de los minutos de su existencia; por otro, el español que lleva a gala su españolismo y presume, sin complejos, de actitudes y acciones que resultan, a todas luces, excesivas a pesar de la buena voluntad que las provoca, que cruza la "zona de confort" de su interlocutor sin pensar en las consecuencias, que, en definitiva, actúa más llevado por los sentimientos que por la razón. La primera conclusión de Claudio marca el desarrollo posterior de la relación entre ambos:

Pero él, Abengoa, estaba claro que vivía en otro mundo, no sé si más feliz, pero sí menos sobresaltado. Su ignorancia de las tremendas gender wars me pareció, contra mi voluntad, tan envidiable como su desenvoltura de narrador inocente, o naïf, para ser más exactos, aunque ya sé que la noción es en sí misma tan discutible, tan lo diré claro, sospechosa, como la del autor, o la de (italics, por supuesto) obra. (Muñoz Molina 1999: 49)

También se critica la corrección política, las políticas departamentales, los congresos (Claudio va a Buenos Aires a participar en un Congreso sobre Borges, donde analizará el poema "Blind Pew", que forma parte de El Hacedor), la vacuidad de una vida sin riesgos, las ideologías castradoras, y hasta el gesto con las manos que se hace en el aire para representar las comillas de un texto. En un encuentro como el que viven obligadamente Claudio y Marcelo se van produciendo transferencias, trasvases, intercambios "transatlánticos" que tienen lugar en la sala de embarque del aeropuerto de Pittsburgh, al calor de las reticencias del primero y de las confidencias del segundo. Todo ello aderezado por la diferencia que, entre sí, manifiestan los discursos de ambos, discursos que son, al mismo tiempo, seña e identidad de cada uno de ellos:

Mi locuaz compatriota había empezado poco a poco a interesarme, pero no por sus devaneos sexuales, sino por los textuales, y por el modo en que yo, como un lector, podría deconstruir su discurso, no desde la autoridad que él le imprimía [...] sino desde mis propias estrategias interpretativas, determinadas a su vez por el hic et nunc de nuestro encuentro, $\mathrm{y}$-para decirlo descaradamente, descarnadamente- por mis intereses. No existe narración inocente, ni lectura inocente, así que el texto es a la vez batalla y botín, o, para usar la equivalencia valientemente sugerida por Daniella Marshall Norris, todo semantic field es en realidad un battlefield ... (Muñoz Molina 1999: 32) 
Claudio busca su identidad; Marcelo, a Carlota Fainberg. Ambos dan rodeos para llegar a su objetivo: "Yo soy el buscador de los tesoros escondidos, como si dijéramos", Ilega a decir Marcelo (1999: 33). En esta búsqueda, que incluye las mayores hazañas y las mayores derrotas en forma de actos ridículos e inmorales, es donde el destino de ambos se encuentra con el del bucanero ciego del poema de Borges (poema que, por cierto, sirve como pórtico a la novela), de quien dice:

\section{$[\ldots]$ a ti también, en otras playas de oro, te aguarda incorruptible tu tesoro: la vasta y vaga y necesaria muerte.}

\subsection{FRESY COOL (ANTONIO J. RODRÍGUEZ)}

Un artefacto narrativo concebido por acumulación de referencias cruzadas entre la alta cultura y baja cultura, de filósofos cool y de noches en Madrizentro (Gran Vía, Lavapiés, Malasaña, Chueca), de garitos donde se reúnen hipsters y universitarios que se enfrentan a profesores que parecen salidos de una película de Quentin Tarantino:

-Bienvenidos a los cursos de literatura del profesor Pleonasmo Chief. Mi nombres es ese, Pleonasmo Chief, y soy el que va a meneársela en vuestra face durante el próximo semestre.

Es posible que a estas alturas ya os hayan hablado de mí. Tengo veintipocos años y soy catedrático de literatura. No me acuesto con mis alumnas. Todavía. Amo a mi mujer. Creo en el posfeminismo. Mi mujer escribe en un periódico de izquierdas. Hasta cierto punto, lamento su trabajo porque lamento cualquier publicación periódica cuyos artículos no vengan firmados por académicos, a excepción de las revistas donde colaboro. Pero a ella la amo. Eso es filosóficamente axiomático. Tiene veinte años. Es decir, es más joven que todos ustedes, pero es que yo también soy más joven que todos ustedes [...]. Soy amigo personal de Harold Bloom y James Wood. Harold acaba de escribirme diciendo que cuándo voy a volver a Massachusets a comer aros de cebolla con él. ¿Sabían que he cagado aros de cebolla en el lavabo de Harold Bloom en Massachusets? Es broma, ja, ja. (Rodríguez 2012: 190-191)

Fresy cool es, además de otras muchas cosas, una novela de campus, uno de cuyos capítulos se articula, a su vez, como un "relato intercalado" a la manera cervantina titulado "Zombis en la Academia Google Text de Letras presentan Una novelita de campus". El modo en que el narrador de Fresy Cool establece los principios teóricos y las premisas narrativas que van a configurar su relato:

La historia de un periodista cínico y de un académico con el alma helada; o mejor, la historia de un narrador desdoblado, que encuentra su tabla de salvación en la, digamos, encrucijada malévola que son los cenáculos literarios, y que recela, al mismo tiempo, o que baila entre una microsociedad pop y otra sectarista, y busca desesperadamente espacios intersticiales. 
La historia de un hombre que pacta con sus lectores la vox pópuli del roman à clef (la historia del latinajo y el extranjerismo entreverado): la escritura peligrosa, como Spanbauer, que halla en este mecanismo, tanto como en la costumbre de integrar teoría, su modo de conducir al extremo la obsesión por lo verosímil de la ficción. (Rodríguez 2012: 17-18)

Todo es extremo en Fresy cool. No solo por la sobreabundancia de niveles narrativos que configuran el relato (algo que, a estas alturas no es excesivamente llamativo), sino por el modo en que estos niveles desatienden cualquier organización y rechazan cualquier tipo de jerarquía semántica o sintáctica. La unidad pretendida es un puro trámite para Antonio J. Rodríguez. Televisión, cine, series, lecturas canónicas, cómics, videojuegos, drogas de diseño, sexo inexperto, canciones de grupos neofolk, individualidad agregada, redes sociales que echan humo, estética punk renovada al calor del lado oscuro de la teoría en este postapocalipsis now. El mundo universitario es una selva y los usos académicos son endémicos del parque temático que termina siendo una especie de Campus S.A. La burla de los excesos pasa por no elevar el tono ni en los momentos de mayor conmoción. Todo se intelectualiza de tal manera que el relato se repliega siempre hacia el territorio de la farsa:

—Lo admiro tanto... Su esposa, sus libros publicados, su casa con piscina, su rechazo a todo lo que huela a viejo: ese olor a papel mojado y ceniciento que tanto seduce a algunas personas de por aquí, ya sabe, su interpretación de la Academia como espacio que ya no es "inocente" ni digno de ser escrito ni aislado necesariamente del mercado: como la antítesis de cualquier centro de creatividad. (Rodríguez 2012: 283-284)

Pero hay también una conciencia de clase en Fresy cool. La del individuo que asciende desde la oralidad provinciana hasta la literacy de la capital y del capital. El desacato a la autoridad representada por los santones de la academia y que pasa por un lenguaje que se desborda sin límites y que no conoce restricciones.

\subsection{EN MEDIO DEL INVIERNO (SAÚl FERNÁNDEZ)}

Estudiantes golfos y pobres. Descreídos, cínicos, burlones. Grunges de chigre. Ácratas de cáterin. Bohemios de postal, noventayochistas sin pedigrí, desnortados, anacrónicos, sablistas, pedantes de garito nocturno, vividores sin vida propia, letraheridos siempre trampeando, adoradores febriles de la noche, lumpen enciclopédico, desangelados en busca de vida interior, guerreros y poetas, caballeros y oficiales sin oficio, modernos vanguardistas, veinteañeros con ínfulas de sabios, hijos de los noventa con deseos ochenteros, vidas cruzadas en las aulas y en los parques. Después, la vida adulta, el mundo real, la desazón, la muerte. Entre la reflexión acongojada y la pedantería de café, la realidad es una bandeja de pinchos en una presentación. Así se mueven los protagonistas de En medio del invierno. 
"La culpa de todo la tiene El club de los poetas muertos", dice uno de sus personajes. Y no le falta razón si consideramos que esta película mediatizó a toda una generación haciéndole creer que estudiar Literatura consistía en subirse a las mesas, recitar "oh capitán mi capitán", hacer teatro nocturno, enfrentarse a familias castradoras, vivir el carpe diem y ser libre; porque, durante años, hizo que los alumnos pensaran que todos los profesores eran Robin Williams. Por el contrario, lo que hay en el campus del Milán ${ }^{13}$ creado por las ficción de Saúl Fernández son profesores que persiguen el complemento dilecto, especialistas en lenguas notas e ignotas, casados en terceras nupcias, con hijos jóvenes y fumadores, pobres de solemnidad, pedigüeños vocacionales. Profesores que explican por enésima vez la égloga tercera de Garcilaso verso a verso, golpe a golpe. Profesores algo desquiciados especialistas en Ercilla perseguidos por psicólogos de guardia:

- Hijos de puta. Todos los psicólogos son unos verdaderos hijos de puta, unos cabrones que carecen de alma, que tienen la sangre helada y el corazón detenido [...]. ¿Quiénes son ellos para decir que sí puedo o no puedo dar clase? Llevo treinta años en la facultad y sé lo que es una explicación. Enseñar es mostrar un camino, decir, ahí lo tienes, síguelo, cuando te encuentres con dificultades ya sabes lo que tienes que hacer. ¡Hijos de puta! Psicólogos, imbéciles... ahora van y dicen que me tienen que enseñar, que solo doy voces, que nadie me respeta, que mis alumnos me detestan. ¿Qué cojones sabrán ellos? Treinta años dando clases... y vienen y me sueltan que la evaluación ha sido un fiasco... que debería pararme a pensar, meditar sobre el problema de fondo... Y dicen... y dicen... que no, que lo mío no es dar clase, que mis clases son una mierda, que nadie sabe de qué hablo. Yo, que llevo treinta años explicando, hablando de los cronistas de Indias, de Sor Juana Inés de la Cruz. ¿Y por qué no evalúan a los alumnos? ¿Qué coño saben ellos de Literatura Iberoamericana? Hijos de puta, psicólogos de mierda...

Aquí, el profesor Gustavo Sendra hizo una pausa, suspiró, se llevó los dedos a las comisuras de los labios, se limpió la babilla disecada y continuó:

-Abran La Araucana... "No las damas, amor, no gentilezas..." ¿o acaso nunca han oído hablar de Alonso de Ercilla, cojones? (Fernández 2001: 24)

Novela de campus, entonces. Y también novela de aprendizaje. Y novela generacional: la de la movida después de la movida. En medio de la narración de los hechos, se encuentran momentos memorables, anécdotas espléndidas, que son como para darse con un cuento en los dientes. Pero hay también mucha soledad, mucha búsqueda, mucho amor, muchas relaciones cruzadas y mucho

\footnotetext{
${ }^{13}$ El ovetense Campus de Humanidades del Milán ya había sido escenario de otra novela algo anterior a En Medio del invierno y que contiene bastantes elementos del subgénero académico. Se trata de la novela corta de Marcelo García Instrucciones psicóticas para no seguir en épocas de crisis (2009), interesante propuesta narrativa cuyo motor no es tanto la sátira académica como el existencialismo juvenil con algunos toques de punk: "El caso es que el ambiente universitario es para nosotros como una droga alteradora de la percepción que nos hace imaginarnos que todavía podemos ser alguien. Nos referimos a alguien que escribe columnas en los periódicos y no necesita atracar sucursales de Inditex para poder vivir de noche con cierto desahogo..." (García 2009: 90).
} 
humor. Este es el libro de las ilusiones y de las decepciones. Hay nombres ocultos, hay distancia, hay engaño. "La puta nostalgia", rezonga un personaje. Y todo se soluciona comiendo en La Tenada, allá por La Callezuela, ese lugar donde se deconstruyen los estómagos, se esferifican las neuronas, entran en emulsión las papilas gustativas y se hace humo la condición intelectual del ser humano.

\subsection{El escolar brillante (Javier Rodríguez Alcázar)}

La más americana de las novelas de campus españolas, la más cercana al espíritu que mueve al género en los Estados Unidos, es El escolar brillante de Javier Rodríguez Alcázar. Todo ello se debe, sin duda, al logro inmediato de integrar una verosímil experiencia personal del narrador como becario-profesor en la Universidad de Saint Louis, y al impulso que la novedad del encuentro con el sistema universitario norteamericano ejerce sobre él. El escolar brillante se articula a partir de la premisa de un equívoco que el narrador-protagonista no deshace: la aceptación de su papel como traductor de alto nivel allí donde él mismo se reconoce como uno más del montón entre los recién licenciados en Filología Inglesa. Esta circunstancia permite desarrollar un doble discurso: el de la narración en primera persona de la experiencia americana del protagonista (vida personal, vida universitaria...) y los fragmentos de la traducción que, con más pena que gloria, lleva a cabo de la novela de J. Bird The Bright Scholar, una obra que trata, para llevarlo todo aún más al extremo, de un español que, como el protagonista, viaja a Estados Unidos. La poca pericia del traductor se va observando a medida que el texto presenta, en el margen derecho de muchas de sus páginas unos recuadros que incluyen los fragmentos traducidos, a medio traducir o con correcciones (que vienen marcadas con una línea superpuesta). El lector asiste entonces a una doble narración: la narración de la American way of life construida sobre lo cotidiano y la falacia traductora nunca resuelta, y la narración de la novela traducida, dos relatos que establecen un diálogo constante entre sí. Al mismo tiempo, el narrador va incluyendo, con el mismo sistema de columna enmarcada, algunas de las lecturas, ejercicios, exámenes, comentarios, etc., que el protagonista hace o propone a sus alumnos (aparecen, entonces, sonetos de Garcilaso de la Vega o fragmentos del Buscón de Quevedo), pero también diálogos de culebrones venezolanos como La perdición de Giselle María, o fragmentos de obras como Remeditos la Ratona y el viejo caliente, poemas escritos por Gloria Rabossi, uno de los personajes de la novela, unas líneas de Introducción a la teoría del conocimiento de A. N. Thomson, o un párrafo del estudio de un (¿una?) desconocido Brunette Latorre titulado Sociología de los estudios humanísticos que, no por casualidad, razona:

Desde este punto de vista, un modelo científico se parece a una traducción. Hay malas traducciones, como hay malos modelos científicos y mapas equivocados que nos conducen a donde no queríamos ir. Pero hay muchas traducciones posibles e igualmente correctas, según distintos criterios, de un mismo texto. (Rodríguez Alcázar 2005: 315) 
La impericia y la torpeza traductora provoca momentos hilarantes ante los continuos errores producidos por "falsos amigos" (estos también abundan en la vida "real" del protagonista), el desconocimiento evidente o las malas artes que, con el tiempo, va aprendiendo. El escolar brillante es una quest que aborda el conocimiento y su lugar en el devenir humano, pero también los asuntos del corazón y de la memoria con tanta naturalidad como artificiosidad se encuentra en un sistema universitario, en un campus, donde el más brillante de los scholars se derrite ante un poema.

\section{CONCLUSIÓN}

La narrativa española reciente no ha sido, como hemos visto, muy dada a dibujar el panorama de un campus como elemento central en el desarrollo de las tramas. Quizá la reverencia hacia el sistema de enseñanza superior durante décadas, y la posterior degradación en el afecto social (a la cual no son ajenos los indiscriminados ataques de varios gobiernos), no hayan sido el mejor caldo de cultivo para la sátira. Hemos revisado algunas manifestaciones recientes de las distintas facetas del humor que ha asumido la novela de campus, especialmente la sátira académica. La llegada de una narrativa menos apegada al argumento verosímil como pilar del relato, y la subsiguiente entrada de modelos narrativos más renovadores ofrecen un impulso a este género. La novela de campus, en cualquiera de sus variantes, como hemos visto, ofrece un valioso testimonio de la vida social y garantiza una crítica de muchos y variados excesos.

\section{OBRAS CITADAS}

Adams, Hazard (1976): The Academic Tribes. Nueva York, Liveright.

Aira, César (1999): El congreso de literatura. Barcelona, Tusquets.

Aldecoa, Josefina (2001): El enigma. Madrid, Alfaguara.

Bajtín, Mijaíl (1986): Problemas de la poética de Dostoievski. México, FCE.

- (1989a): La cultura popular en la Edad Media y en el Renacimiento. El contexto de François Rabelais. Madrid, Alianza.

— (1989b): Teoría y estética de la novela. Madrid, Taurus.

Ballart, Pere (1994): Eironeia. La figuración irónica en el discurso literario moderno. Barcelona, Quaderns Crema.

Barraza Macías, Arturo (2005): "Saber y poder: el papel de las universidades". En: <http:// www.odiseo.com.mx/2005/07/barraza-saberypoder.htm>.

Beltrán, Luis (2002): La imaginación literaria. La seriedad y la risa en la literatura occidental. Barcelona, Montesinos.

Besora, Max (2014): La tècnica meravellosa. Barcelona, Males Herbes.

Bevan, David (ed.) (1990): University Fiction. Amsterdam/Atlanta, Rodopi.

Booth, Wayne C. (1983): The Rhetoric of Fiction. Chicago, The University of Chicago Press, $2^{\mathrm{a}}$ ed.

Bosco, Mark, y Connor, Kimberly Rae (eds.) (2007): Academic Novels As Satire: Critical Studies of An Emerging Genre. Londres, Mellen Press. 
Bostock, Paddy (1989): Poststructuralism, Postmodernism, and British Academic Attitudes, with Special Reference to David Lodge, Malcolm Bradbury and Gabriel Josipovice. Tesis doctoral inédita. North London Polytechnic University.

Bou, Enric (2006): "Campus universitarios: deriva y simulacro", Lars. Cultura y Ciudad, n. ${ }^{\circ}$ 5, p. 6.

Bourdieu, Pierre (2008): Homo academicus. Buenos Aires, Siglo xxı.

Caram, Richard G. (1980): The Secular Priest: A Study of the College Professor as Hero in Selected American Fiction (1955-1977). Tesis doctoral inédita. San Louis University.

Casas Ros, Antoni (2010): Enigma. Barcelona, Seix Barral.

Cercas, Javier (2000): El inquilino. Barcelona, El Acantilado.

- (2005): La velocidad de la luz. Barcelona, Tusquets.

(2007): El vientre de la ballena. Barcelona, Tusquets.

Concha, Ángeles de la (1988): "La novela universitaria: foro de teorías sobre la ficción y de ficcionalización de teorías", Revista Canaria de Estudios Ingleses, n. 17, pp. 169-196.

Costa, Jordi (ed.) (2010): Una risa nueva. Posthumor, parodias y otras mutaciones de la comedia. Molina de Segura, Nausícaä.

Courtoisie, Rafael (2008): Goma de mascar. Madrid, Lengua de Trapo.

Crews, Frederick (1963): The Pooh Perplex: A Freshman Casebook. Nueva York, E.P. Dutton.

- (2002): Posmodern Pooh. Nueva York, North Point Press.

Critcheley, Simon (2002): On Humor. Londres / Nueva York, Routledge.

Derrida, Jacques (1989): "Las pupilas de la Universidad. El principio de razón y la idea de universidad", Anthropos. Revista de Documentación Científica de la Cultura, Suplemento n. ${ }^{\circ} 13$, pp. 62-74.

Donoso, José (1995): Donde van a morir los elefantes. Madrid, Alfaguara.

Dotras, Ana M. (1994): La novela española de metaficción. Gijón, Júcar.

Elliot, Robert C. (1960): The Power of Satire. Princeton, Princeton University Press.

Escarpit, Robert (1962): El humor. Buenos Aires, EUDEBA.

Fernández de la Vega, Ceferino (1967): El secreto del humor. Buenos Aires, Nova.

Fernández, Saúl (2011): En medio del invierno, Oviedo, Septem.

Ferré, Juan Francisco (2009): Providence. Barcelona, Anagrama.

Fry, William F. (1968): Sweet Madness: A Study of Humor. Palo Alto, Pacific Books.

Gamboa, Santiago (2009): Necrópolis. Barcelona, Belacqua.

García Rodríguez, Javier (2002): "Apuntes para la caracterización de la literatura de campus con un muestrario (necesariamente) incompleto de obras", Clarín. Revista de Nueva Literatura, n. ${ }^{\circ}$ 37, pp. 3-13.

— (2009): "Contra Aristóteles vivíamos mejor: materiales para una improbable historia reciente de la Escuela de Chicago". En: Amelia Sanz Cabrerizo (comp.): Teoría literaria española con voz propia. Madrid, Arco/Libros, pp. 83-101.

García, Marcelo (2009): Instrucciones psicóticas para no seguir en épocas de crisis. Oviedo, Septem.

Gómez, Sergio (2002): La obra literaria de Mario Valdini. Madrid, Lengua de Trapo.

Hernández, José Antonio (2010): "El humor: un procedimiento creativo y recreativo". En: Ulpiano Lada Ferreras y Álvaro Arias-Cachero Cabal (eds.): Literatura y humor. Estudios teórico-críticos. Oviedo, Servicio de Publicaciones de la Universidad de Oviedo, pp. 43-56. 
Jauss, Hans Robert (1986): Experiencia estética y hermenéutica literaria. Ensayos en el campo de la experiencia estética. Madrid, Taurus.

Jurado López, Manuel (2008): Cómo matar a un poeta. Madrid, EDAF.

Kerr, Lucile (1997): "Academic relations and Latin American fictions", The Journal of Narrative Technique, vol. 27, n. ${ }^{\circ}$, pp. 25-33.

Lambertsson Björk, Eva (1993): Campus Clowns and the Canon: David Lodge's Campus Fiction. Umea, The Printing Office of the University of Umea.

Leal Canales, José Antonio (2010): El testamento del becario. Sevilla, Algaida.

Leuzinger, Mirjam Anna (2014): "Realidades imaginadas y academia: Un momento de descanso de Antonio Orejudo". En: Antonio J. Gil González (ed): Las sombras del novelista: AutorrepresentacioneS // 3. Dijon, Editions Orbis Tertius, pp. 219-230.

Lindo, Elvira (2002): Algo más inesperado que la muerte. Madrid, Alfaguara.

Lisherness, Nancy Lee (1985): The American College Novel: A Microcosm of Female Academe. Tesis doctoral inédita. Arizona State University.

Lyons, John O. (1962): The College Novel in America. Carbondale, Southern Illinois University Press.

Maddok-Cowart, Donna Samal (1989): The World, the Flesh, and the Devil: the Professor in Sixteen Post-1950 Academic Novels. Tesis doctoral inédita. University of Georgia.

Mañas, José Ángel (1996): Soy un escritor frustrado. Madrid, Espasa.

Marías, Javier (1989): Todas las almas. Madrid, Anagrama.

Martínez, Guillermo (2004): Los crímenes de Oxford. Barcelona, Destino.

- (2012): Yo también tuve una novia bisexual. Barcelona, Destino.

Meers, Geneva (1953): Victorian Schoolteachers in Fiction. Tesis doctoral inédita. Northwestern University.

Monnickendam, A. (1989): "The Comic Academic Novel", BELLS, n. ${ }^{2}$ 2, pp. 153-171.

Moret, Xavier (1997): El impostor sentimental. Barcelona, Emecé.

Morin, Violette (1982): "El chiste". En: VV.AA.: Análisis estructural del relato. Barcelona, Editorial Buenos Aires, pp. 121-145.

Moseley, Merrit (ed.) (2007): The Academic Novel: New and Classic Essays. Chester, Chester Academic Press.

Muñoz Molina, Antonio (1999): Carlota Fainberg. Madrid, Alfaguara.

Oloixarac, Pola (2010): Las teorías salvajes. Madrid, Alpha Decay.

Orejudo, Antonio (2011): Un momento de descanso. Barcelona, Tusquets.

Paraíso, Isabel (1995): Literatura y psicología. Madrid, Síntesis.

Parra Luna, Francisco (2011): Campus adentro. Madrid, Huerta \& Fierro.

Paulson, Ronald (1967): The Fictions of Satire. Baltimore. The Johns Hopkins University Press.

Paz Soldán, Edmundo (2001): La materia del deseo. Madrid, Alfaguara.

Pérez Collados, José María (2011): El tren de cristal. Sevilla, Renacimiento.

Piqueras de Noriega, Javier (2003): La cátedra. Barcelona, Meteora.

- (2005): El congreso. Barcelona, Meteora.

Pueo, Juan Carlos (2001): "Ridens et Ridiculus". Vincenzo Maggi y la teoría humanista de la risa. Zaragoza, Tropelías.

_- (2002): Los reflejos en juego (Una teoría de la parodia). Valencia, Tirant lo Blanc. 
Ransell-Kóster, Claudia (2001): "El humor en El mundo es un pañuelo de David Lodge", Quaderns de Filología. Estudios literarios vi. Humor i literatura, pp. 185-200.

Reati, Fernando, y Gómez Ocampo, Gilberto (1998): "Académicos y gringos malos: la universidad y la barbarie cultural en la novela latinoamericana", Revista Iberoamericana, vol. LXIV, n. ${ }^{\circ}$ 184-185, pp. 587-609.

Reddall, David John (2010): The Laughing Academy: A Comparative Analysis of Academic satires. Tesis doctoral inédita. University of Alberta.

Rivera de la Cruz, Marta (2009): La importancia de las cosas. Barcelona, Planeta.

Rodríguez Alcázar, Javier (2005): El escolar brillante. Barcelona, Mondadori.

Rodríguez, Antonio J. (2012): Fresy cool. Barcelona, Mondadori.

Rossen, Janice (1993): The University in Modern Fiction: When Power is Academic. Nueva York, St. Martin's Press.

Rueda, Ana (2014): "Autoficción y novela en clave: Un momento de descanso de Antonio Orejudo". En Ana Casas (ed.): El yo fabulado. Nuevas aproximaciones críticas a la autoficción. Madrid/Frankfurt, Ibertoamericana/Vervuert, pp. 289-305.

Sáiz García, María Soledad (2001): La evolución del sistema educativo inglés de enseñanza superior y la novela académica (1944-1988). Tesis doctoral inédita. Universidad de Oviedo.

Salvador, Gregorio (2002): El eje del compás. Barcelona, Planeta.

Sánchez Lorenzo, Sixto (2003): De Bestiis Universitati. Madrid, Dykinson.

Schoentjes, Pierre (2003): Poética de la ironía. Madrid, Cátedra.

Showalter, Elaine (2005): Faculty Towers: the Campus Novel and Its discontents. Filadelfia, University of Pennsylvania Press.

Sosa Antonietti, Marcela Beatriz (1999): "La ficción de Narciso: El impostor sentimental de Xavier Moret". Trabajo Final del Curso de Doctorado "Novelas que explican teorías: modelos teórico-literarios en obras de ficción", Universidad de Valladolid.

Torrente Ballester, Gonzalo (1992): La muerte del decano. Barcelona, Planeta.

Tusset, Pablo (2011), Oxford 7. Barcelona, Destino.

Verrone, Patricia (1999): The Image of the Professor in American Academic Fiction: 19801997. Tesis doctoral inédita. Seton Hall University.

Victoria, Marcos (1958): Ensayo preliminar sobre lo cómico. Buenos Aires, Losada.

Villamía, Luis (2015): "El despliegue de la autoficción en la Academia: la novela de campus en la narrativa española actual", Pasavento. Revista de Estudios Hispánicos, vol. III, n. 1 , pp. 43-55.

Villar Flor, Carlos (2004): Calle menor. Madrid, Sial.

VV. AA. (1980): Humor, ironía, parodia. Madrid, Fundamentos (Espiral / Revista 7).

Wiegenstein, Steven Christopher (1997): The Contemporary Academic Novel: A Study in Genre. Tesis doctoral inédita. University of Missouri.

Womack, Kenneth (2002): Postwar Academic Fiction: Satire, Ethics, Community. Houndmills, Palgrave.

Worcester, David (1960): The Art of Satire. Nueva York, Rusell and Rusell.

Ziv, A. y Diem, J. M. (1989): El sentido del humor. Bilbao, Deusto. 